\title{
ATRIBUIÇÕES DE CAUSALIDADE À VIOLÊNCIA PARA PESSOAS EM SITUAÇÃO DE RUA
}

Mariana Luíza Becker da Silva

Universidade Federal de Santa Catarina

Andréa Barbará da Silva Bousfield

Universidade Federal de Santa Catarina

Andréia Isabel Giacomozzi

Universidade Federal de Santa Catarina

Maiara Leandro

Universidade Federal de Santa Catarina
Recebido em: 09/08/2019

$1^{\text {a }}$ revisão em: 11/12/2019

Aceito em: 25/02/2020

\section{RESUMO}

No Brasil muitas pessoas em situação de rua morrem por violência. Diversos fatores influenciam para que a violência ocorra, tornando-se relevante a Teoria de Atribuição de Causalidade para a compreensão desta temática, pois viabiliza o estudo das explicações espontâneas fornecidas aos acontecimentos sociais. Assim, este estudo tem objetivo de compreender os aspectos influenciadores da violência para pessoas em situação de rua. Trata-se de um estudo qualitativo, exploratório e descritivo. Foram realizadas entrevistas semiestruturadas com 91 pessoas em situação de rua. Para análise das entrevistas, foi realizado a análise categorial temática, a qual foram analisadas as categorias: Contexto Social, Contexto Intrínseco, Álcool e outras drogas e Reprodução da Violência. Por fim, verificou-se que os participantes atribuíram a violência perpetuada pelo outro como causalidade interna, e quando perpetuada por si próprio foram por motivos externos.

Palavras-chave: violência; situação de rua; causalidade; morador de rua. 


\section{ATTRIBUTION OF CAUSALITY OF THE VIOLENCE FOR HOMELESS}

\section{ABSTRACT}

In Brazil many homeless people die from violence. Several factors influence the occurrence of violence, making the Causality Attribution Theory relevant to the understanding of this theme, as it enables the study of spontaneous explanations provided to social events. Thus, this study aims to understand the influencing aspects of violence for homeless people. It is a qualitative, exploratory and descriptive study. Semi structured interviews were conducted with 91 homeless people. For the analysis of the interviews, the thematic categorical analysis was realized, which was analyzed the categories: Social Context, Intrinsic context, Alcohol and other drugs and Reproduction of violence. Finally, it was found that the participants attributed the violence perpetuated by the other as internal causality, and when perpetuated by themselves were for external reasons.

Keywords: violence; homeless; causality; homelessness.

\section{ATRIBUICIÓN DE CAUSALIDAD DE VIOLENCIA PARA PERSONAS SIN HOGAR}

\section{RESUMEN}

En Brasil, muchas personas sin hogar mueren a causa de la violencia. Varios factores influyen en la aparición de la violencia, lo que hace que la teoría de la atribución de la causalidad sea relevante para la comprensión de este tema, ya que permite el estudio de las explicaciones espontáneas proporcionadas a los eventos sociales. Por lo tanto, este estudio tiene como objetivo comprender los aspectos influyentes de la violencia para las personas sin hogar. Es un estudio cualitativo, exploratorio y descriptivo. Se realizaron entrevistas semiestructuradas con 91 personas sin hogar. Para el análisis de las entrevistas, se realizó el análisis categórico temático, que analizó las categorías: Contexto social, Contexto Intrínseco, Alcohol y otras drogas y Reproducción de la violencia. Finalmente, se encontró que los participantes atribuyeron la violencia perpetuada por el otro como causalidad interna, y cuando se perpetuaron por sí mismos fueron por razones externas.

Palabras clave: violencia; personas sin hogar; causalidad; sin hogar. 


\section{INTRODUÇÃO}

Nossa sociedade possui alguns grupos que convivem mais com a violência diária do que outros por conta das desigualdades sociais e dos processos de exclusões. Exemplo disso é a população em situação de rua, que diariamente lida com este fenômeno. Este grupo possui em comum a pobreza extrema, a ausência de moradia convencional e por este motivo utilizam de espaços públicos ou áreas degradadas para morar por um determinado tempo ou às vezes permanentemente (Presidência da República, 2009).

A sociedade tende a atribuir identidades cristalizadas à população em situação de rua associadas à valores negativos, além de serem reconhecidos como ameaçadores, reforçando a sua exclusão (Mattos \& Ferreira, 2004; Silva, 2013). Jodelet (2017) apresenta reflexões em torno do medo social compartilhado, que desumaniza os sujeitos considerados como uma ameaça para excluí-los moralmente da sociedade. Esses preconceitos contribuem para a violência contra essa população, pois se naturaliza e legitima práticas discriminatórias e violentas e favorece as relações de exploração e dominação (Alcantara, Abreu, \& Farias, 2015; Jodelet, 2011; Moura Jr., Ximenes, \& Sarriera, 2013; Nonato \& Raiol, 2016). Para Bourdieu (1983), a violência deve ser apreendida como uma forma de sociabilidade, que valida normas sociais e serve como um dispositivo de poder e de controle.

A partir disso, a violência ocorre de diferentes formas contra a população de rua, além de advir de todos os lados, inclusive de outras pessoas que também estejam na mesma situação (Nonato \& Raiol, 2016; Pereira, 2008). De acordo com Heerde e Hemphill (2014), a vida nas ruas possui uma série de desafios envolvendo fatores estruturais, como a marginalização, desigualdade, estigma, instabilidade financeira, vitimizações, entre outros, e para lidar com isso, muitas pessoas em situação de rua utilizam como estratégia o uso da violência. Assim, as pessoas em situação de rua normalmente também praticam ações violentas, pois de acordo com Campos (2016) e Huey (2016), nas ruas há regras baseadas na independência, dureza e violência, como uma forma de conquistar o respeito, dominação e proteção.

Um fator adicional que influencia a violência contra essa população são as violações do poder público que frequentemente desrespeitam o direito à vida e à segurança, além de elaborar políticas públicas insuficientes e ineficientes (Andrade, Costa, \& Marquetti, 2014; Kunz, 2012; Martinelli, Oliveira, \& Santos, 2017; Nonato, \& Raiol, 2016). Além disso, as intervenções com as pessoas em situação de rua são muitas vezes higienistas, com o objetivo de esconder as desigualdades, sendo impositivas e violentas (Andrade et al., 2014). Campos (2016) apresenta que a violência praticada pelo aparato policial foi apontada frequentemente pelas pessoas em situação de rua, utilizando de violência física e verbal para expulsá-los de locais públicos, recolher pertences, realizar "revistas", entre outros. 
A mídia também possui uma grande influência para que a violência ocorra. Algumas pesquisas (Almeida, 2011; Ferreira \& Alves, 2015; Oliveira \& Feitosa, 2016; Resende, 2016; Resende \& Santos, 2012; Silva \& Huning, 2015) estudaram o que a mídia apresentava em relação a população em situação de rua, sendo que alguns resultados apontaram representações pejorativas desse grupo, sendo que mesmo quando são vítimas de violência ainda assim são culpabilizadas. Deste modo, a mídia acaba por individualizar a violência e tornando-a intrínseca às vítimas (Ferreira \& Alves, 2015).

A partir dessas reflexões, compreende-se que a violência é constitutiva da vida nas ruas (Huey, 2016), sendo este um fenômeno complexo, que muitas vezes é atribuída a causas simplistas, que auxiliam na manutenção do status quo e na reprodução de mais violências. Deste modo, uma estratégia teórica para o aprofundamento da temática é a utilização da Teoria da Atribuição de Causalidade, a qual segundo Tróccoli (2011) refere-se à construção que os indivíduos realizam de diversas inferências e explicações do porquê e as causas das ocorrências observáveis, sendo estas causas percebidas pelo sujeito e não causas reais. Assim, essas atribuições causais têm profundas influências sobre nossas reações afetivas e comportamentais (Tróccoli, 2011). A teoria de atribuição de causalidade tem suas origens no trabalho pioneiro de Heider (1958), segundo o qual as pessoas tendem a se utilizar de causas internas (disposicionais, próprias ao indivíduo) ou externas (situacionais, devidas a circunstâncias físicas ou sociais) para explicar os acontecimentos do cotidiano. Tais posições foram posteriormente refinadas e aprofundadas por outros autores, como por exemplo, Weiner (2005), o qual acrescenta que um mesmo problema pode ser percebido como decorrente de causas diferentes, de acordo com as atribuições causais que ocorrem no processo perceptivo.

Salienta-se que para o estudo do fenômeno das violências, Porto (2015) afirma ser necessário o não julgamento normativo ou valorativo, pois o que está em questão não é o "correto", mas o que é vigente. Assim, é relevante buscar as relações entre as violências e suas representações, não para avaliá-las como falsas ou verdadeiras, mas por reconhecê-las como um dado bruto da realidade. Dessa forma, entendese a importância de contextualizar atribuição causal adotada, tendo em vista que ao elaborar as explicações espontâneas aos acontecimentos sociais, as pessoas também apresentam aspectos representacionais, associadas a crenças e valores (Hewstone, 2001).

Devido à relevância desta temática, a literatura científica apresenta alguns trabalhos que discutem em seus resultados aspectos influenciadores da violência nas situações de rua (Alles, 2010; Campos, 2016; Ferreira \& Alves, 2015; Fiori, Xavier, Lobato, Carretta, \& Kebbe, 2015; Heerde \& Hemphill, 2014; Nonato \& Raiol, 2016; Oliveira \& Feitosa, 2015; Pereira, 2008; Resende \& Santos, 2012; Resende, 2016; Rosa \& Bretas, 2015; Silva, 2013). No entanto, até o momento não foram encontradas pesquisas que tenham como foco essa questão, que articulem a Teoria da Atribuição de Causalidade com os aspectos influenciadores de violência 
e que apresentem resultados sobre essa questão na perspectiva das pessoas em situação de rua.

Com isso, considera-se este estudo inédito e relevante para a comunidade científica e para a sociedade em geral, tendo em vista que foi proporcionado um espaço de escuta para as pessoas em situação de rua para suas crenças e explicações sobre as influências das relações violentas nas ruas. Com isso, esta pesquisa teve como objetivo compreender os aspectos influenciadores da violência para pessoas em situação de rua e fatores associados, como o contexto, crenças, valores e situações vivenciadas que interferem nas explicações dadas.

\section{MÉTODO}

Trata-se de um estudo de abordagem qualitativa, natureza exploratória e descritiva (Sampieri, Collado, \& Lucio, 2013). Além disso, a pesquisa possui corte transversal, por ter ocorrido a coleta de dados num determinado tempo cronológico (Richardson, 2009).

\section{PARTICIPANTES}

Participaram desta pesquisa 91 pessoas em situação de rua que se adequaram aos critérios pré-estabelecidos pelas pesquisadoras. Como critério de inclusão, os participantes deveriam estar em situação de rua por no mínimo um mês, ser maiores de 18 anos, concordância em participar da pesquisa e ocupar as ruas da Grande Florianópolis.

\section{INSTRUMENTOS}

Para coleta de dados, foi utilizado como instrumento um roteiro de entrevista semiestruturada construída pelas pesquisadoras. As perguntas abordaram o que os participantes acreditam que influencia as relações violentas, assim como questões sociodemográficas que auxiliaram na contextualização dos participantes. As questões sociodemográficas abordavam dados pessoais (idade, sexo, naturalidade, tempo de permanência nas ruas, onde normalmente dormia), aspectos relacionais (estado civil, se possui filhos, quantos, se estavam sob sua responsabilidade, se costuma vê-los e a frequência), escolaridade e ocupação (até qual série estudou, se possuía ocupação e qual), aspectos de saúde (se possuía alguma questão de saúde física ou mental, se usava álcool e outras drogas, qual e com que frequência), e outros (se acessava algum serviço, qual e se participava de algum movimento social e qual).

\section{PROCEDIMENTOS}

O estudo foi submetido ao Comitê de Ética, com a aprovação sob o parecer número 2.572.261. As pesquisadoras entraram em contato com os profissionais que trabalham no Serviço Especializado de Abordagem Social dos quatro 
municípios que compõe a região da Grande Florianópolis (Biguaçu, Palhoça, São José e Florianópolis). Deste modo, foi possível adquirir indicações de locais (praças centrais, marquises, locais abandonados, terminais de ônibus, entre outros) e pessoas que poderiam participar do estudo. As entrevistas ocorreram no local em que a pessoa se encontrava, em espaços públicos. Durante as entrevistas, foi apresentado os objetivos desta pesquisa e entregue o Termo de Consentimento Livre e esclarecido (TCLE). Também foi realizado o pedido de autorização para que que as pesquisadoras pudessem gravar a entrevista. E ainda, como auxílio na busca por participantes foi utilizado a técnica de bola de neve, em que um participante indica outro, e assim sucessivamente (Flick, 2009).

As entrevistas foram transcritas e analisadas pela técnica de análise categorial temática, que desmembra o conteúdo total e agrupa as categorias conforme os grupos de elementos que possuem características em comum (Bardin, 2009). A análise de conteúdo refere-se a um trabalho minucioso, que se inicia com a leitura flutuante e segue em busca de identificar núcleos de sentido, que foram codificados e agrupados em categorias mais amplas.

\section{RESULTADOS E DISCUSSÃO}

A presente pesquisa contou com a participação de 91 pessoas, destas apenas 16 mulheres. Esta diferença ocorre, segundo Rosa e Bretas (2015), devido ao fato de a população em situação de rua ser predominantemente composta por homens, o que intensifica a relação desigual de poder, tornando as mulheres mais vulneráveis nesta condição. Esta situação é ampla e complexa, sendo necessário abarcá-la em outro espaço/artigo. Todos os participantes ocupavam a região da Grande Florianópolis, sendo a média de 5 anos e 8 meses nas ruas (DP: 7 anos e 8 meses). Entre estes, 38 pessoas estavam em situação de rua há menos de dois anos, 18 estavam entre 2 a 8 anos, 21 há mais de 8 anos, 14 pessoas intercalavam entre períodos na rua e como residente.

Em relação à idade, 56 possuíam entre 31 a 50 anos, 28 pessoas possuíam entre 18 a 30 anos e sete com mais de 51 anos, sendo a média de 36 anos (DP: 10 anos). Dentre os participantes, 21 eram naturais do interior de Santa Catarina, 20 do Rio Grande do Sul, 18 eram autóctones (nativos), 15 oriundos do Paraná, 14 de outros estados e três provenientes de outros países (dois uruguaios e uma chilena). Em relação ao local em que normalmente dormiam, 57 afirmaram dormir em praças, embaixo de marquises ou viadutos, 24 relataram nunca dormir no mesmo lugar e 10 em frente de lugares públicos ou com movimento.

Quanto à escolaridade, 43 participantes possuíam ensino fundamental incompleto, 21 com ensino médio completo, 11 possuíam o ensino fundamental completo, oito possuíam ensino superior incompleto, sete com ensino médio incompleto, e um concluiu o ensino superior. Em relação à atividade laboral, 46 afirmaram trabalhar com artesanato, reciclagem, servente, flanelinha, vendedor no sinaleiro ou outras atividades autônomas e 45 afirmaram não exercer nenhuma atividade remunerada. 
Dentre os participantes, 65 relataram não possuir companheiro (a) e 26 possuíam companheiro (a). Além disso, 38 possuíam mais de um filho, 31 afirmaram não possuir filhos e 22 possuíam um filho. Dentre os que possuíam filhos, 39 estavam com a mãe da criança/adolescente, nove com a família extensa, sete eram adultos e um encontrava-se institucionalizado. Além disso, 33 pessoas haviam visto o/os filhos há menos de um ano, 13 nos últimos cinco anos, oito há mais de cinco anos e dois nunca viram seus filhos.

Em relação a questões de saúde física e/ou mental, 57 pessoas afirmaram não possuir nenhuma questão física/mental, 16 relataram possuir algum comprometimento físico, 11 indicaram possuir questões tanto físicas como mentais e seis afirmaram possuir alguma questão de saúde mental. Quanto ao uso de álcool e outras drogas, 34 participantes afirmaram usar pelo menos uma das substâncias mencionadas (álcool, maconha, cocaína e crack), 24 afirmaram usar todas (considerado por eles como "total flex"), 23 pessoas utilizavam duas das quatro substâncias e 10 afirmaram não usar nada. Dentre os que utilizavam álcool e outras drogas, 59 disseram todos os dias, 12 afirmaram usar toda hora, sete usavam até três vezes na semana e três a cada 15 dias. Alguns relataram que não usavam com frequência, porém quando perguntado objetivamente, diziam que tinham usado naquele dia.

Quanto ao acesso a rede de serviços públicos dos municípios, 29 pessoas afirmaram acessar serviços da assistência social, 26 afirmaram não acessar nenhuma instituição, 20 disseram acessar serviços de saúde e de assistência social e 13 usavam somente serviços de saúde. Além disso, sete pessoas relataram frequentar igrejas como um apoio as necessidades básicas. Em relação à participação em movimentos sociais, apenas 13 relataram participar do Movimento Nacional da População em Situação de Rua (MNPR).

A análise do conteúdo gerada das entrevistas semiestruturadas, resultou em quatro categorias de análise: Contexto social; Contexto Intrínseco; Álcool e outras drogas; e, Reprodução da Violência. Cada categoria é constituída por subcategorias, as quais são compostas de unidades temáticas apresentadas adiante. Estas unidades retratam um conjunto de significados análogos, baseadas nas narrativas. A compilação em subcategorias de temas maiores auxilia na compreensão das categorias de análise e associadas aos objetivos do estudo.

\section{CONTEXTO SOCIAL}

A primeira categoria de análise, nomeada de Contexto Social, possui 30,67\% da codificação aberta realizada, e é compreendida por tudo aquilo que se refere ao contexto social em que a população em situação de rua vivência e o que contribui para essas pessoas sofrerem ou praticarem a violência. No presente estudo, o contexto social é compreendido pela Desigualdade, Governo e falta de políticas públicas, Preconceito, Mídia, Histórico relacional, e as suas respectivas unidades de análise, como demonstrado na Tabela 1. 
Tabela 1.

Categoria de análise nomeada como Contexto Social.

\begin{tabular}{|c|c|c|}
\hline CATEGORIA & SUBCATEGORIA & UNIDADES DE ANÁLISE \\
\hline \multirow{5}{*}{$\begin{array}{l}\text { Contexto } \\
\text { Social } \\
(f=30,67 \%)\end{array}$} & $\begin{array}{l}\text { Desigualdade } \\
(f=43,48 \%)\end{array}$ & $\begin{array}{c}\text { Diferenças sociais } \\
\text { Falta de oportunidades e de } \\
\text { trabalho } \\
\text { A vida na rua como influenciadora } \\
\text { de tensão } \\
\text { Diferenças sociais }\end{array}$ \\
\hline & $\begin{array}{c}\text { Governo e Falta de políticas } \\
\text { públicas } \\
(f=23,91 \%)\end{array}$ & $\begin{array}{c}\text { Governo corrupto } \\
\text { (In) Justiça } \\
\text { Falta de políticas públicas e não } \\
\text { garantia de direitos fundamentais }\end{array}$ \\
\hline & $\begin{array}{l}\text { Preconceito } \\
(f=15,21 \%)\end{array}$ & $\begin{array}{c}\text { Da população em geral } \\
\text { Da polícia }\end{array}$ \\
\hline & $\begin{array}{c}\text { Mídia } \\
(f=4,34 \%)\end{array}$ & $\begin{array}{l}\text { Como propagadora da cultura } \\
\text { da violência }\end{array}$ \\
\hline & $\begin{array}{l}\text { Histórico relacional } \\
\qquad(f=13,04 \%)\end{array}$ & $\begin{array}{l}\text { Violência intrafamiliar } \\
\text { Amizades "ruins" }\end{array}$ \\
\hline
\end{tabular}

A subcategoria Desigualdade foi caracterizada por meio das unidades temáticas nomeadas de diferenças sociais; falta de oportunidade e de trabalho; e a vida na rua como influenciadora de tensão, exemplificadas nesta ordem, nos seguintes excertos:

"Está muito feio, as pessoas poderiam ser mais humildes, as pessoas que têm mais poderiam ajudar quem tem menos" (mulher, 38 anos, 3 meses na rua);

"A se eles dessem uma oportunidade, se viessem dar serviço, a gente não estava nessa vida, porque é tudo trabalhador, os caras pedem trabalho, mas ninguém dá serviço, dizem que somos vagabundos, chamam a polícia, que bate em nós" (homem, 26 anos, 16 meses na rua);

"As pessoas não terem condições de terem uma vida digna, e acabam caindo na vida errada, na violência" (homem, 32 anos, 5 anos na rua).

Nessas unidades temáticas as pessoas em situação de rua relacionaram as questões sociais como influenciadores no humor e na indignação o que provoca entre eles práticas violentas, assim como acreditam que outras pessoas que 
detenham o poder utilizam-se dessas diferenças sociais para legitimar suas ações violentas como, por exemplo, a polícia e os governantes, também mencionados com frequência.

Com isso, o Governo e a falta de políticas públicas foram outra subcategoria compondo as unidades temáticas nomeadas de Governo corrupto; (in)justiças; falta de políticas públicas e não garantia de direitos fundamentais, exemplificadas nesta ordem, nos seguintes trechos:

"Os órgãos públicos que se submetem a roubar, tirar o dinheiro do povo, desde um palito de fósforo que você está pagando, os órgãos públicos são os que mais roubam" (homem, 38 anos, 2 meses na rua);

"Os políticos tudo roubando, e a gente sabendo e não pode revidar, eles vão presos, e tem luxo, isso é uma violência, para mim todo mundo é igual. Por que eles podem roubar o tanto que quiserem, e se você rouba 10 reais, você leva tapa na cara e chute" (homem, 42 anos, 28 anos na rua);

"O que influencia a violência é o não cumprimento dos meus direitos, direitos que são garantidos pela própria Constituição, direitos que me colocam na situação de vulnerabilidade" (homem, 40 anos, 16 anos na rua).

Esses relatos vão ao encontro de pesquisas (Andrade et al., 2014; Kunz, 2012; Martinelli, Oliveira, \& Santos, 2017; Nonato, \& Raiol, 2016), que pontuam que o poder público viola frequentemente os direitos à vida, liberdade, igualdade, segurança e elabora políticas públicas insuficientes e ineficientes. E ainda, em concordância com Alles (2010) já citado neste estudo, as intervenções realizadas pelo poder público muitas vezes são totalmente higienistas para que a desigualdade não fique explícita para a sociedade.

A subcategoria Preconceito expressou as unidades de análise chamadas: da população em geral; e da polícia, exemplificadas nesta ordem, nos seguintes trechos:

"As pessoas só veem as coisas ruins, não veem se tu tens profissão, se tem passagem ou não, só veem a diferença, isso influencia muito a violência" (homem, 30 anos, 17 anos na rua);

"É porque a polícia não gosta de morador de rua, eles tiram todo mundo para casqueiro, todo mundo que mora na rua de casqueiro" (homem, 40 anos, 11 anos na rua).

A expressão casqueiro é uma gíria local pejorativa que pode ter diferentes significados, neste caso utilizou-se no sentido de indicar pessoas que usam crack com frequência e são malvistas pela sociedade. Com isso, os entrevistados pontuam que o preconceito contribui para a discriminação que segundo Allport (1954) se refere ao componente comportamental, é o efeito imediato do 
preconceito. Ela ocorre através do tratamento injusto, conduta e comportamento desigual e desfavorável em relação a um grupo ou pessoas, no caso de uma atitude negativa (Techio, 2011).

Assim, observa-se que a violência contra população em situação de rua é concretizada a partir do preconceito, da discriminação e da intolerância. Delfin, Almeida e Imbrizi (2017) referem que a população como um todo associa esquemas tipificadores à população em situação de rua, contribuindo para a violência simbólica em decorrência de representações pejorativas. Deste modo, conforme já citado neste estudo, a identidade destas pessoas está associada a valores negativos (Mattos \& Ferreira, 2004) assim legitimando as práticas discriminatórias e violentas (Alcantara et al., 2015; Jodelet, 2011; Moura et al., 2013; Nonato \& Raiol, 2016). Além disso, em relação ao preconceito da polícia, Campos (2016) aponta em sua pesquisa que policiais utilizam frequentemente de violência física e verbal para qualquer situação.

A subcategoria Mídia compôs a unidade de análise nomeada como propagadora da cultura da violência, como ilustrado em:

"A mídia que propaga o modo de vida egoísta como se fosse saudável, de você buscar e ter posse, até a questão das novelas mostra muita coisa de traição, ao invés de tentar passar para a população uma outra visão" (33 anos, 3 meses na rua).

Sobre as comunicações em massa, Moscovici (1981) afirma que estas ampliam a difusão de conhecimento e formas de pensamento social, tornando-se dispositivos de disseminação de crenças, normas, valores e representações sociais. Carvalho, Freire e Vilar (2012) referem que não há uma responsabilidade direta da mídia pela promoção da violência, no entanto, a mídia explora o fenômeno da violência, ampliando sua importância e às vezes envolvendo-os em uma aura de glória, com isso exercendo uma influência negativa nas dinâmicas sociais e culturais.

A subcategoria denominada de Histórico relacional expressou as unidades de análise nomeadas como: violência intrafamiliar e amizades ruins, exemplificadas nesta ordem, nos seguintes excertos:

"Vem de casa, porque um filho de um casal violento ele tende a ficar do mesmo jeito, cresce vendo aquilo, e vai acreditar que tudo tem que conseguir na força, e então começa a agredir as pessoas, eu acho que é muito da família, da criação" (mulher, 18 anos, 6 meses na rua);

"Acho que o quê influencia são as amizades ruins, sempre tem alguém para fazer a maldade" (mulher, 54 anos, 2 meses na rua).

Em relação à violência intrafamiliar, Bee (2003) afirma que bater em uma criança em longo prazo traz consequências negativas, como aprender que o uso da violência física é um método eficaz para resolver problemas. Além disso, o conceito 
de intergeracionalidade auxilia a compreensão do processo da violência, a qual é a transmissão de valores, que faz com os padrões relacionais se mantenham por gerações, porém não necessariamente uma criança que presencia violência será um adulto violento (Moré \& Krenkel, 2014). Assim, o contexto social em que o sujeito se desenvolveu influencia suas ações, porém não diretamente, pois há mais elementos que também influenciam suas práticas.

Esta última subcategoria foi apresentada predominantemente por mulheres. Nesse sentido, algumas pesquisas (Biscotto, 2015; Campos, 2016; Rosa \& Bretas, 2015) apontam que a motivação para a ida e permanência de mulheres para as ruas foi relacionada ao histórico de violências sofridas no contexto familiar, a renda insuficiente e a ruptura dos vínculos sociais. De acordo com Antoni e Muñoz (2016), o ambiente da rua é representada pela figura do homem, provedor desempregado, sendo relacionada à mulher, a imagem idealizada do ambiente doméstico, limpo, que mora em casa. As diferenças de gênero são construídas socialmente e arraigadas na sociedade. Com isso, observa-se nas falas de algumas mulheres em situação de rua uma relação com o ambiente doméstico.

Ressalta-se que as atribuições de causalidade compartilhadas na categoria "Contexto social" se associaram em sua maioria a participantes do Movimento Nacional da População em Situação de Rua (MNPR). Este movimento luta por igualdade e por direitos (Pizzato, 2012), é atualmente presente na realidade das pessoas em situação de rua da região da Grande Florianópolis, tendo em vista que se realizam reuniões semanais para a discussão de problemáticas, fortalecimento desta população e elaboração de estratégias para a luta por direitos (Schuck, 2017). Assim, verificou-se falas mais "politizadas" dos participantes que frequentam as reuniões do MNPR.

\section{CONTEXTO INTRÍNSECO}

A segunda categoria de análise, nomeada de Contexto Intrínseco, possui $28 \%$ da codificação aberta realizada, e é compreendida por tudo aquilo que se refere a explicações intrínsecas como influenciadoras da violência nas ruas. Esta categoria é compreendida pela Personalidade, Humor, Ateísmo, Ócio, Ações inoportunas, e as suas respectivas unidades de análise, demonstrado na Tabela 2. 
Tabela 2.

Categoria de análise nomeada como Contexto Intrínseco.

\begin{tabular}{|c|c|c|}
\hline CATEGORIA & SUBCATEGORIA & UNIDADES DE ANÁLISE \\
\hline \multirow{11}{*}{$\begin{array}{l}\text { Contexto } \\
\text { Intrínseco } \\
(f=28 \%)\end{array}$} & \multirow{3}{*}{$\begin{array}{l}\text { Personalidade } \\
\qquad(\mathrm{f}=32,55 \%)\end{array}$} & Algo biológico \\
\hline & & Falta de índole e virtude \\
\hline & & Falta de autocontrole e respeito \\
\hline & \multirow{2}{*}{$\begin{array}{l}\text { Humor } \\
(\mathrm{f}=15 \%)\end{array}$} & $\begin{array}{c}\text { Sentimentos negativos, de raiva e } \\
\text { ódio }\end{array}$ \\
\hline & & Acordar de mau-humor \\
\hline & \multirow{2}{*}{$\begin{array}{l}\text { Ações inoportunas } \\
\qquad(f=13,95 \%)\end{array}$} & $\begin{array}{l}\text { Fazer coisas erradas a outras } \\
\text { pessoas }\end{array}$ \\
\hline & & $\begin{array}{c}\text { Não saber "chegar" nos lugares e } \\
\text { nas pessoas }\end{array}$ \\
\hline & Ócio & Tempo ocioso \\
\hline & $(f=11,62 \%)$ & Acontecer "do nada" \\
\hline & Ateísmo & Não ter fé \\
\hline & $(f=6,98 \%)$ & Uma força do mal \\
\hline
\end{tabular}

A subcategoria Personalidade foi caracterizada pelas unidades de análise nomeadas como: Algo biológico; falta de índole e virtude; e falta de controle e respeito, ilustradas nesta ordem, nos seguintes trechos:

"O que influencia a violência é ela já ser violenta por natureza" (mulher, 23 anos, 4 meses na rua);

"Acho que é a pessoa ser ignorante, ou ela roubar alguma coisa da outra, xingar, mexer com alguém da família, mexer com a esposa de alguém (homem, 30 anos, 8 meses na rua);

"Eu acho que a violência acontece pela falta de autocontrole das pessoas, e pela falta de respeito com os outros, porque ninguém respeita mais ninguém hoje em dia, ninguém tem mais respeito pela história do outro" (mulher, 21 anos, 2 anos na rua).

A subcategoria denominada de Humor expressou as unidades de análise: Sentimentos negativos, de raiva e ódio; e acordar de mau-humor, demonstradas nesta ordem, nos seguintes trechos:

"A inveja e a raiva, isso para mim influencia, não para mim, para as pessoas que estão magoadas com a vida, tem mágoa de estar em situação de rua, mas não é o que ele quer para sua vida e 
acabam usando isso contra os outros" (homem, 22 anos, 6 anos na rua);

"Às vezes as pessoas acordam já com raiva, estressadas, acontece alguma situação que ela já quer extravasar, quer fazer alguma coisa que tornam as coisas piores ainda" (homem, 23 anos, 2 meses na rua).

A atribuição ao humor ainda abarca a individualidade dos sujeitos, porém como ilustrado nas falas, há uma contextualização dos sentimentos. Conforme Silva Junior e Belloc (2018), permanecer nas ruas é complexo, envolve estar na margem da presença-ausência social. Esta invisibilidade materializa-se nas dificuldades no cotidiano, na fome, no frio, nas práticas discriminatórias e violentas. A rua é um lugar de precariedades, vulnerabilidade e ausências, o que contribui para as explicações dadas pelos entrevistados em relação ao mau humor em decorrência da vida que se vive.

A subcategoria Ações inoportunas, abrangeu as unidades de análise: Fazer as coisas erradas a outras pessoas; e não saber 'chegar' nos lugares e nas pessoas, apresentadas nesta ordem, nas seguintes falas:

"fazer coisas erradas para as pessoas, o único problema é esse, porque tu vai ser violentado, vai ser cobrado, então sim, fizesse isso, fizesse aquilo. Agora se todo mundo fizesse tudo certinho, não ia ter violência, até ia ter, mas menos." (homem, 41 anos, 8 anos na rua);

"Eu sei que todo mundo tem que saber chegar, com educação, com cuidado em se pronunciar, porque a pessoa também vai ter o mesmo cuidado que você, mas se você chega em um lugar com agressividade, chamando disso ou daquilo ela também vai fazer o mesmo" (homem, 34 anos, 7 meses na rua).

O Ócio compôs as unidades de análise: Tempo ocioso; e acontecer do nada, ilustradas nesta ordem, nos seguintes excertos:

"Falta de ocupação, você vê muita gente com uma falta de ocupação muito incrível, ficam o dia inteiro parados e começam a martelar coisa de crime" (homem, 26 anos, 6 meses na rua);

"A violência chega do nada, na rua é assim, está de boa, daqui a pouco acontece uma coisa, depois com outra pessoa ou contigo, é sempre assim" (mulher, 35 anos, 8 anos na rua).

Em relação a esta última unidade de análise, Silva e Huning (2015) pontuam a naturalização da violência, em que a vida na rua é relegada a um responsabilizarse por si, com uma banalização da violência que sofrem como algo intrínseco à vida que possuem. 
E por último, a subcategoria Ateísmo compôs as unidades de análise: Não ter fé; e uma força do mal, demonstradas nesta ordem, nos seguintes trechos:

"O que ajuda a violência é o coração sem Jesus Cristo, só maldade" (homem, 36 anos, 12 anos na rua);

"Como eu acredito no mundo espiritual, eu acredito que é uma força do mau o que influencia mais a violência, as pessoas estão escolhendo mais o caminho do mal" (homem, 34 anos, 2 anos na rua).

Essa subcategoria e o "ócio" demonstram a culpabilização em torno da moralidade. Para a compreensão da categoria como um todo, pode-se utilizar diferentes teorias da psicologia social, como bem fez Rodrigues (2018) em seu trabalho sobre a influência social, desenvolvimento moral e o papel das minorias ativas em um processo de mudança. $\mathrm{O}$ autor refere que a maioria das pessoas se encontra no nível Convencional, em que ocorre com maior facilidade a influência social, conformismos e seu julgamento moral resulta da pressão do grupo dominante. Assim, as atribuições causais associadas se relacionam à representação dominante propagada em nossa sociedade.

Nesse sentido, em concordância com Almeida (2011) e Ferreira e Alves (2015), a mídia vem apresentado preconceitos com uma imagem negativa da população em situação de rua. Estes sujeitos são raramente ouvidos e, quando são, tendem a tomar emprestada a representação dominante, repetindo o discurso "moralista" já existente. Compreende-se que a partir da informação, as pessoas em situação de rua veem o que a mídia propaga em relação à violência nas ruas, contribuindo para o seu posicionamento frente ao fenômeno, o que influencia também suas práticas (Moscovici, 2012).

Além disso, conforme Porto (2015), a compreensão da violência sempre corre o risco de se atribuir explicações individuais e morais a algo que é socialmente produzido. As questões pessoais devem ser consideradas, mas não explicam fenômenos sociais. Porto (2015) aponta que a utilização da violência se refere a estratégias, para eficácia, resolução de conflitos, oportunidade, afirmação de identidades, explosão de raivas, frustrações, dentre outros. Nessa direção, Silva (2004) apresenta o conceito de sociabilidade violenta, a qual considera que no cotidiano há uma ordem social dominante organizada pela força, o que explica alguns dos trechos que foram ilustrados nas unidades de análise.

\section{ÁlCOOL E OUTRAS DROGAS}

A terceira categoria de análise, nomeada de Álcool e outras drogas, possui 23,3\% da codificação aberta realizada, e é compreendida por tudo aquilo que se refere ao uso de substâncias psicoativas e sua relação estreita nas práticas violentas no contexto da rua. No presente estudo, a categoria é compreendida pela Alteração de humor, Roubos e conflitos, e as suas respectivas unidades de análise, como demonstrado na Tabela 3. 
Tabela 3.

Categoria de análise nomeada como Álcool e outras drogas.

\begin{tabular}{|c|c|c|}
\hline CATEGORIA & SUBCATEGORIA & UNIDADES DE ANÁLISE \\
\hline \multirow[b]{2}{*}{$\begin{array}{c}\text { Álcool e } \\
\text { outras drogas } \\
(f=23,33 \%)\end{array}$} & $\begin{array}{l}\text { Alteração de humor } \\
\qquad(f=68,57 \%)\end{array}$ & $\begin{array}{l}\text { Causador de maior agressividade } \\
\text { Perda de consciência dos atos }\end{array}$ \\
\hline & $\begin{array}{l}\text { Roubos e conflitos } \\
\qquad(f=31,42 \%)\end{array}$ & $\begin{array}{c}\text { Roubos para obter mais álcool e } \\
\text { outras drogas } \\
\text { Conflitos entre pessoas em } \\
\text { situação de rua para ter mais } \\
\text { álcool e outras drogas }\end{array}$ \\
\hline
\end{tabular}

A subcategoria Alteração de humor foi nomeada por meio das unidades de análise: Causador de maior agressividade; e perda de consciência dos atos, ilustradas nesta ordem, nos seguintes trechos:

"Morador de rua se está se drogando, às vezes estoura com alguém, pelas drogas" (homem, 30 anos, 5 anos na rua);

"Eu vi moradores de rua drogados e o que eles praticam, nossa eles fazem coisas absurdas e depois não se lembram mais, fazem. no momento do barato" (homem, 43 anos, 1 mês na rua).

Já a subcategoria denominada de Roubos e conflitos expressou as unidades de análise: Roubos para obter mais álcool e outras drogas; e conflitos entre pessoas em situação de rua para ter mais álcool e outras drogas, apresentadas nesta ordem, nos seguintes trechos:

"A droga, o crack principalmente, porque o vício ajuda a tu começar a roubar e já vem a violência nisso" (homem, 22 anos, 2 anos na rua);

"Às vezes tem gente que bebe aqui na praça, também porque não passou a garrafa para o outro beber lá já é motivo para brigar" (homem, 26 anos, 1 ano na rua).

Nesta categoria os fatores influenciadores da violência circundam em torno do uso de substâncias psicoativas. Nessa direção, Heerde e Hemphill (2014) em sua pesquisa encontrou que os tipos de comportamento fisicamente violentos e a vitimização física vivenciada por jovens em situação de rua foram geralmente associados ao aumento do uso de substâncias psicoativas. Para além disso, este mesmo uso é observado na fala dos participantes como uma estratégia de enfrentamento à vida nas ruas. Nesse sentido, Campos (2016) e Monteiro e Almeida (2015) afirmam que o uso de álcool e outras drogas são frequentemente imbricadas na vida dessas pessoas para a manutenção da vida na rua, na atenuação da condição que se vive, no auxílio para determinados comportamentos, como 
ficar acordado a noite como uma estratégia para não sofrer violências e como forma de lidar com as dificuldades do cotidiano.

Constata-se nas falas novamente que há uma reprodução da representação dominante em torno do uso de álcool e outras drogas. De acordo com Fiorati et al. (2015), há no imaginário social uma concepção sobre o uso de substâncias psicoativas como sempre associado à violência. Assim, o fortalecimento dos discursos sobre as relações entre situação de rua, drogas e ações violentas contribui para as estigmatizações. A lógica da redução de danos neste sentido é essencial, pois compreende o uso de álcool e outras drogas a partir de uma relação, que tende a não patologizar ou moralizar a experiência do uso, ressaltar o respeito e autonomia dos sujeitos, não ignora os prejuízos do uso, mas admite que a interrupção é um processo que envolve diferentes decisões para além da abstinência total (Oliveira, Sampaio, \& Saldanha, 2015).

\section{REPRODUÇÃO DA VIOLÊNCIA}

A quarta categoria de análise, nomeada de Reprodução da Violência, possui 18\% da codificação aberta realizada, e é compreendida pelas re (ações) frente à realidade violenta das ruas. No presente estudo, a categoria é compreendida pela Necessidade de revidar, a Expectativa do outro, e as suas respectivas unidades de análise, como demonstrado na Tabela 4.

Tabela 4.

Categoria de análise nomeada como Reprodução da Violência.

\begin{tabular}{|c|c|c|}
\hline CATEGORIA & SUBCATEGORIA & UNIDADES DE ANÁLISE \\
\hline \multirow{5}{*}{$\begin{array}{l}\text { Reprodução } \\
\text { da Violência } \\
\qquad(f=18 \%)\end{array}$} & \multirow{4}{*}{$\begin{array}{l}\text { Necessidade de revidar } \\
\qquad(\mathrm{f}=80,77 \%)\end{array}$} & Para se defender \\
\hline & & Para a violência não se repetir \\
\hline & & Orgulho pessoal \\
\hline & & Reciprocidade das ações \\
\hline & $\begin{array}{l}\text { Expectativa do outro } \\
\qquad(\mathrm{f}=19,23 \%)\end{array}$ & $\begin{array}{c}\text { Pela cobrança dos outros por } \\
\text { uma resposta à violência } \\
\text { ocorrida }\end{array}$ \\
\hline
\end{tabular}

A subcategoria necessidade de revidar foi nomeada por meio de Para se defender; para a violência não se repetir; orgulho pessoal; e reciprocidade das ações, ilustradas nesta ordem, pelas seguintes falas:

"Ele foi botar a mão no meu bolso para me roubar e eu botei ele dentro do rio, só que eu fui me defender, eu não fui para com a violência que nem ele, então quer dizer, violência gera violência" (homem, 52 anos, 4 anos na rua); 
"O que influencia é aquele mau elemento, que espera a gente dormir para roubar, e quando a gente descobre a gente tem que dar uma camaçada de pau para não fazer de novo" (homem, 60 anos, 5 anos na rua);

"Eu não gosto de brincadeirinha, da tiração, isso para mim já vai me subindo e tem determinados momentos que tu tem que fazer primeiro, que nem meu pai dizia, não brigue, não bata em ninguém, mas se alguém bater em você, bata, seja agressivo, seja violento" (homem, 20 anos, 4 anos na rua);

"É a forma das pessoas tratarem os outros, que se você me tratar bem eu vou te tratar bem, porque todo mundo é trabalhador e é gente boa, mas depende do tratamento que você dá, se você tratar mal uma pessoa eu vou tratar mal do mesmo jeito" (homem, 34 anos, 5 anos na rua).

Além disso, a subcategoria denominada de Expectativa do outro expressou a unidade de análise: Pela cobrança dos outros por uma resposta à violência ocorrida como no trecho a seguir:

"Te cobram a tua violência, como assim fulano fez isso com você e você não vai revidar, não, eu não quero revidar, não preciso disso, mas te cobram uma violência, te cobram uma posição" (homem, 26 anos, 6 meses na rua).

A partir das unidades de análise ilustradas acima, observa-se que a agressão e a hostilidade entre as pessoas que estão em situação de rua são provenientes da coletividade a que pertencem (Alles, 2010). Campos (2016) e Huey (2016) afirmam que nas ruas há regras apoiadas na dureza e na violência, com o objetivo de conquistar o respeito, dominação e proteção. Estas ditas regras corroboram com a subcategoria Expectativa do outro, a qual rege alguns comportamentos, considerados aceitos ou não aceitos pelo grupo de pertença, como reagir com violência a alguma prática violenta. Huey (2016) frisa a necessidade de contextualizar a violência na rua, tendo em vista que há uma tendência em ignorar os aspectos estruturais e culturais que transformam a violência em uma solução necessária para evitar pró ativamente a vitimização nesse contexto. Assim, a violência torna-se constitutiva nas vivências e relações grupais.

Todas as categorias demonstram os aspectos influenciadores da violência e fatores associados, que circulam entre as pessoas em situação de rua. Com isso, a Teoria da Atribuição de Causalidade se torna fundamental para a compreensão destes resultados. Assim, relacionou-se este estudo com os aspectos teóricos da atribuição causal (Heider, 1958), considerando as covariações, princípios (Kelley, 1973), tendenciosidades e dimensões causais (Weiner, 2005).

Na primeira categoria Contexto social ressalta-se a atribuição externa e impessoal às situações de violência: o contexto gera sentimentos negativos que influenciam os comportamentos violentos, ou mesmo o próprio contexto (sistema econômico 
vigente, governo, políticas públicas, preconceito, mídia, relações interpessoais) que violenta de diversas formas. Na categoria Contexto Intrínseco verifica-se que há diferenças conforme as subcategorias. Em relação à Personalidade as práticas violentas são associadas às características biológicas, as quais não dependem da vontade da pessoa, com isso, diz-se que são atribuições externas e impessoais. Em contrapartida, as outras subcategorias se relacionam ao humor, ao ateísmo, ao ócio e ações inoportunas, as quais demonstram que a pessoa possui autonomia em suas ações e que contribuem para que a violência ocorra. Na categoria Álcool e outras drogas os efeitos do uso ultrapassam a vontade do sujeito e o vício é considerado mais forte que a sua autonomia de escolha, com isso há também a atribuição externa e impessoal. E por último, a Reprodução da Violência é a única categoria em que os participantes se colocam como praticantes de violência, nas outras três, há explicações das causas pelas quais os outros praticam a violência. Nesta categoria, a utilização da violência pelos participantes é relacionada à violência provocada pelo outro, sendo esta atribuição externa e impessoal.

Os resultados são consistentes com algumas tendenciosidades consequentes de algumas atribuições causais. As categorias Contexto Intrínseco e Reprodução da Violência podem ser compreendidas como uma tendência de realizarmos uma atribuição interna quando observamos o comportamento dos outros sem considerar possíveis variáveis situacionais; e, uma atribuição externa ao nosso próprio comportamento principalmente quando este é negativo, como ser violento devido à violência do outro (Weiner, 2005).

Importante destacar que a categoria contexto social foi a mais frequente entre as atribuições, seguida de Contexto Intrínseco, álcool e outras drogas e, Reprodução da Violência. Com isso, verifica-se que apesar das diversas atribuições realizadas pelas pessoas em situação de rua serem associadas à representação dominante que circunda na sociedade, coexistem atribuições causais que vão contra à hegemônica, demonstrando uma reflexão sobre contextos macrossociais, preconceitos, violência estrutural, simbólica, entre outros. Essas reflexões possuem associação dos participantes com o MNPR, e também com alguns não participantes, o que evidencia o movimento das minorias ativas (Moscovici, 2011).

Ressalta-se por fim, que as reflexões não tiveram como objetivo afirmar se as explicações dadas pelos entrevistados estão certas ou erradas. Porto (2015) alerta para a importância do não julgamento normativo ou valorativo nos estudos sobre a violência, pois o que está em questão é o que é vigente no cotidiano.

\section{CONSIDERAÇÕES FINAIS}

Esta pesquisa possibilitou a apreensão dos aspectos influenciadores da violência para pessoas em situação de rua e seus fatores associados, como o contexto, crenças, valores e situações vivenciadas que interferem nas explicações dadas, além de reflexões sobre as atribuições causais sobre esse fenômeno. Os resultados apresentam conteúdos relacionados ao contexto social, com explicações micro e 
macrossociais, às características inerentes de algumas pessoas, aos efeitos do uso de substâncias psicoativas, que ao mesmo tempo em que influenciam a violência, tornam-se estratégias de sobrevivência e as reações violentas frente a práticas de violência, consideradas como regras implícitas das relações de convivência nas ruas.

Além disso, observou-se que houve diferenças entre as explicações sobre os fatores influenciadores da violência devido aos diferentes contextos, crenças, ideologias e vivências que as pessoas em situação de rua possuem. Dentre as explicações surgiram relatos de vida e de ações violentas sofridas e praticadas nas ruas. Histórias que envolveram a complexidade da sobrevivência da violência, suas relações no cotidiano e a sua naturalização.

A partir dos resultados, verificou-se que os participantes tiveram a tendência a realizar uma atribuição interna à violência cometida pelos outros e atribuição externa aos seus próprios comportamentos. Além disso, conclui-se que as pessoas em situação de rua muitas vezes tendem a reproduzir as representações dominantes, repetindo discursos já existentes, que individualiza a violência perpetrada nas ruas. Destaca-se também que as práticas consideradas violentas são constitutivas das relações complexas que se estabelecem nas ruas, a partir de sociabilidades com regras e morais próprias. Assim, é necessário compreendê-la integralmente ao pensar em políticas públicas e práticas profissionais efetivas, que busquem a construção de espaços de diálogos para a circulação do conhecimento sobre seus direitos, para o fortalecimento desta população e para contribuir na desmoralização dos aspectos influenciadores da violência. Além disso, considerase importante o papel do Movimento Nacional da População em Situação de Rua no processo de politização desta população.

Como limitações da pesquisa, considera-se que a coleta de dados ocorreu nas ruas, o que influenciou no tempo das entrevistas, além da dificuldade em avaliar se as (os) entrevistadas (os) estavam sob efeito de substâncias psicoativas, assim, apenas as (os) que estavam com efeitos mais perceptíveis foram excluídas (os) da pesquisa. Com isso, os resultados deste estudo devem ser relativizados e considerados em conjunto com outros estudos. Outro aspecto refere-se à amostra de conveniência, que limita a generalização dos resultados. Considerando a relevância da temática e o número restrito de pesquisas que abarcam a problemática, conclui-se que outros estudos precisam ser realizados com o objetivo de contribuir para o maior suporte empírico aos achados desta pesquisa.

\section{REFERÊNCIAS}

Alcantara, S. C., Abreu, D. P., \& Farias, A. A. (2015). Pessoas em situação de rua: Das trajetórias de exclusão social aos processos emancipatórios de formação de consciência, identidade e sentimento de pertença. Revista Colombiana de Psicología, 24(1), 129-143. doi:10.15446/rcp.v24n1.40659.

Alles, N. L. (2010). Boca de rua: Representações sociais sobre população de rua em um jornal comunitário. (Dissertação de mestrado). Universidade Federal do Rio Grande do Sul, Rio Porto Alegre, Brasil. 
Allport, G. W. (1954). The nature of prejudice. Reading, MA: Addison-Wesley.

Almeida, D. A. C. (2011). Morador de rua: Da questão social para a questão midiática. Puçá: Revista de Comunicação e Cultura na Amazônia, 1(1), 77- 102.

Amazarray, M. R., \& Koller, S. H. (1998). Alguns aspectos observados no desenvolvimento de crianças vítimas de abuso sexual. Psicologia Reflexão e Crítica, 11(3), 559-578. doi:10.1590/S010279721998000300014

Andrade, L. P., Costa, S. L., \& Marquetti, F. C. (2014). A rua tem um ímã, acho que é a liberdade: Potência, sofrimento e estratégias de vida entre moradores de rua na cidade de Santos, no litoral do Estado de São Paulo. Saúde e Sociedade, 23(4), 1248-1261. doi:10.1590/S010412902014000400011.

Antoni, C., \& Munhós, A. A. R. (2016). As violências institucional e estrutural vivenciadas por moradoras de rua. Psicologia em Estudo, 21(4), 641-651. doi:10.4025/psicolestud.v21i4.31840.

Bardin, L. (2009). Análise de Conteúdo. (Ed. revista e actualizada). Lisboa: Edições 70.

Bee, H. (2003). A criança em desenvolvimento. Porto Alegre, RS: Artes Médicas.

Biscotto, P. R. (2015). Viver em situação de rua: Experiência de mulheres que utilizam o albergue para pernoitar. (Dissertação de mestrado). Universidade de São Paulo, São Paulo, Brasil.

Bourdieu, P. (1983). Questões de Sociologia. Rio de Janeiro, RJ: Marco Zero.

Campos, D. A. (2016). Os efeitos das relações de gênero nas trajetórias dos moradores de rua do município de Florianópolis (SC). (Dissertação de mestrado). Universidade Federal de Santa Catarina, Florianópolis, Brasil.

Carvalho, D. W, Freire. M. T., \& Vilar G. (2012). Mídia e violência: Um olhar sobre o Brasil. Revista Panamericana de Salud Publica, 31(5), 435-8.

Cerqueira, D., Lima, R. S., Bueno, S., Neme, C., Ferreira, H., Coelho, D., \& Merian, F. (2018). Atlas da violência. Rio de Janeiro, RJ: Ipea e FBSP.

Delfin, L., Almeida, L. A. M., \& Imbrizi, J. M. (2017). A rua como palco: Arte e (in)visibilidade social. Psicologia \& Sociedade, 29, e158583. doi:10.1590/1807-0310/2017v29158583.

Ferreira, F. V., \& Alves, M. P. (2015). Representações sociais dos moradores de rua no jornal correio braziliense: Exclusão, dessemelhança e violência. Revista Interdisciplinar Científica Aplicada 9(3), 35-56.

Fiorati, R. C., Xavier, J. J. S., Lobato, B. C., Carretta, R. Y. D., \& Kebbe, L. M. (2015). Iniquidade e exclusão social: Estudo com pessoas em situação de rua em Ribeirão Preto/SP. Revista Eletrônica Gestão e Saúde, 3, 2120-2135. doi:10.18673/gs.v0i0.22440.

Flick, U. (2009). Desenho da pesquisa qualitativa. Porto Alegre, RS: Artmed.

Gil, A. C. (2009). Métodos e técnicas de pesquisa social (6a ed.). São Paulo, SP: Ed. Atlas S. A.

Heerde, J. A., \& Hemphill, S. A. (2014). A systematic review of associations between perpetration of physically violent behaviors and property offenses, victimization and use of substances among homeless youth. Children and Youth Services Review, 44, 265-277. doi:10.1016/j.childyouth.2014.06.020.

Heider, F. (1958). The Psychology of Interpersonal Relations. New York, NY: John Wiley \& Sons.

Hewstone, M. (2001). Representações sociais e causalidade. In D. Jodelet (Ed.), As representações sociais. Rio de Janeiro, RJ: EdUERJ.

Huey, L. (2016). There is no strength in emotions: The role of street enculturation in influencing how victimized homeless women speak about violence. Journal of Interpersonal Violence, 31(10), 1817-1841. doi:10.1177/0886260515570749.

Jodelet, D. (2011). Os processos psicossociais da exclusão. In B. Sawaia (Ed.), As artimanhas da exclusão: Análise psicossocial e ética da desigualdade social. (11a ed.) Petrópolis, RJ: Vozes.

Jodelet, D. (2017). Representações Sociais e mundos de vida (Ulup, Trad.). São Paulo, SP: Fundação Carlos Chagas.

Kelley, H. H. (1973). The processes of causal attribution. American Psychologist, 28(2), 107-128. doi:10.1037/h0034225.

Krug, E. G, Mercy, J. A., Dahlberg, L. L, \& Zwi, A. B. (2002). The World report on violence and health. Geneva: World Health Organization.

Kunz, G. S. (2012). Modos de vida da população em situação de rua: Narrativas de andanças nas ruas de Vitória/ES. (Dissertação de mestrado). Universidade Federal do Espírito Santo, Vitória Brasil. 
Martinelli, K. C. O., Oliveira, E. M., \& Santos, V. P. (2017). População em situação de rua e a questão da violência. In Anais do $5^{\circ}$ Encontro Internacional de Política Social e $12^{\circ}$ Encontro Nacional de Política Social. Vitória, ES.

Mattos, R. M., \& Ferreira, R. F. (2004). Quem vocês pensam que (elas) são? Representações sobre as pessoas em situação de rua. Psicologia \& Sociedade, 16(2), 47-58.

Minayo, M. C. S., \& Souza, E. R. (1998). Violência e saúde como um campo interdisciplinar e de ação coletiva. História, Ciências, Saúde, 4(3), 513-531.

Monteiro, F. K. V., \& Almeida, L. P. (2015). A exclusão social de mulheres moradoras de rua: Questões de gênero e políticas sociais. In P. C. Silva (Ed.), Territorio(s), Género, Trabajo y Politicas Públicas em América Latina. Votorantim, SP: Editora Provocare.

Moré, C. L. O. O., \& Krenkel, S. (2014). Violência no contexto familiar. In E. B. S. Coelho (Ed.), Atenção a homens e mulheres em situação de violência por parceiros íntimos. Florianópolis, SC: UFSC.

Moscovici, S. (1981). On social representation. In J. P. Forgas (Ed.), Social cognition: Perspectives on everyday understanding. London: Academic Press.

Moscovici, S. (2003). Representações sociais: Investigações em psicologia social. Petrópolis, RJ: Vozes.

Moscovici, S. (2011). Psicologia das minorias ativas. Petrópolis, RJ: Vozes.

Moscovici, S. (2012). A psicanálise, sua imagem e seu público. Petrópolis, RJ: Vozes (Publicado originalmente em 1961).

Moura, J. F., Ximenes, V. M., \& Sarriera, J. C. (2013). Práticas de discriminação às pessoas em situação de rua: Histórias de vergonha, de humilhação e de violência em Fortaleza, Brasil. Revista de Psicología, 22(2), 18-28. doi:10.5354/0719-0581.2013.30850.

Nonato, D. N., \& Raiol, R. W. G. (2016). Invisíveis sociais: A negação do direito à cidade à população em situação de rua. Revista de Direito Urbanístico, Cidade e Alteridade, 2(2), 81-101. doi:10.26668/IndexLawJournals/2525-989X/2016.v2i2.1321

Oliveira, F. J., \& Feitosa, M. Z. S. (2016). Representações sociais e população em situação de rua: A visibilidade construída pela mídia. Revista FSA, 13(2), 226-243. doi:10.12819/2016.13.2.12

Oliveira, R., Sampaio, S. S., \& Saldanha, W. S. (2015). Redução de danos no atendimento a sujeitos em situação de rua. Argumentum, 7(2), 221-234. doi:10.18315/argumentum.v7i2.10440.

Pereira, C. P. (2008). Rua sem Saída: Um estudo entre a relação entre o Estado e a população em situação de rua de Brasília. (Dissertação de mestrado). Universidade de Brasília, Brasília, Brasil.

Pizzato, R. M. S. (2012). A trajetória do protagonismo dos grupos e dos movimentos da população em situação de rua. In A. E. Dornelles, J. Obst, \& M. B. Silva (Eds.). A rua em movimento: Debates acerca da população adulta em situação de rua na cidade de Porto Alegre (pp. 6986). Belo Horizonte, MG: Didática Editora do Brasil.

Porto, M. S. G. (2006). Crenças, valores e representações sociais da violência. Sociologias, 8(16), 250 273.

Porto, M. S. G. (2015). A violência, entre práticas e representações sociais: Uma trajetória de pesquisa. Revista Sociedade e Estado, 30(1). doi:10.1590/S0102-69922015000100003.

Presidência da República. Casa Civil. Subchefia para Assuntos Jurídicos (2009). Decreto No 7.053. Institui a política nacional para inclusão social da população em situação de rua e seu comitê intersetorial de acompanhamento e monitoramento, e dá outras providências. Brasília, DF: Presidente da República. Disponível em http://www.planalto.gov.br/ccivil_03/_ato20072010/2009/decreto/d7053.htm

Resende, V. M. (2016). Discursive representation and violation of homeless people's rights: Symbolic violence in Brazilian online journalism. Discourse \& Communication, 10(6), 596-613. doi:10.1177/1750481316674778.

Resende, V. M., \& Santos, A. A. (2012). A representação de pessoas em situação de rua quando vítimas de chacina: Uma análise discursiva crítica. Revista Latinoamericana de Estudios del Discurso, 12(2). doi:10.35956/v.12.n2.2012.p.81-102.

Richardson, R. J. (2009). Pesquisa social: Métodos e técnicas. São Paulo, SP: Atlas.

Rodrigues, P. R. G. (2018). Influência social, minorias ativas e desenvolvimento moral. Psicologia \& Sociedade, 30(1). doi:10.1590/1807-0310/2018v30173402.

Rosa A. S, \& Brêtas A. C. P. (2015). Violence in the lives of homeless women in the city of São Paulo, Brazil. Interface (Botucatu), 19(53), 275-85. doi:10.1590/1807-57622014.0221.

Sampieri, R. H., Collado, C. F., \& Lucio, P. B. (2013). Metodologia de Pesquisa. São Paulo, SP: McGraw Hill. 
Schuck, A. L. (2017). "Nossa fome não é por comida, é por direitos e políticas públicas..." Cartografias de processos de resistência com o Movimento da População em situação de Rua em Santa Catarina. (Dissertação de mestrado). Universidade Federal de Santa Catarina, Florianópolis, Brasil.

Silva, S. A. (2013). População em situação de rua no Rio de Janeiro: Novos tempos, velhos métodos. Psicologia Política, 13(27), 337-350.

Silva, L. A. M. (2004). Sociabilidade violenta: Por uma interpretação da criminalidade contemporânea no Brasil urbano. Sociedade e Estado, 19(1), 53-84. doi:10.1590/S0102-69922004000100004.

Silva, W. N., \& Hüning, S. M. (2015). De morador de rua a criminoso. Athenea Digital, 15(2), 141-165. doi: 10.5565/rev/athenea.1479.

Silva Junior, D. V., \& Belloc, M. M. (2018). Habitar invisível: Produção de vida e cuidado na experiência urbana. Interface Comunicação, Saúde, Educação, 22(67), 1065-1075. doi:10.1590/180757622017.0452.

Souza, M. S. (2007). Representações sociais, polícia e violência: Um estudo sobre a violência policial. Scientia Plena, 3(5), 75-82

Techio, E. M. (2011). Estereótipos sociais como preditores das relações intergrupais. In E. M. Techio \& M. E. O. Lima. (Eds.), Cultura e produção das diferenças: Estereótipos e preconceito no Brasil, Espanha e Portugal. Brasília, DF: Technopolitik.

Tróccoli, B. T. (2011) Cognição social. In C. V. Torres \& E. R. Neiva (Eds.), Psicologia social: Principais temas e vertentes. (pp. 80-99). Porto Alegre, RS: Artmed.

Wagner, W. (1998). Sócio-gênese e características das representações sociais. In A. S. P. Moreira \& D. C. de Oliveira (Eds.), Estudos interdisciplinares de representação social (pp. 3-25). Goiânia, GO: $A B$.

Weiner, B. (2005). Motivation from an attributional perspective and the social psychology of perceived competence. In A. J. Elliot \& C. S. Dweck (Eds.), Handbook of competence and Motivation. (pp. 156-172). New York, NY: Guilford Press.

\section{AGRADECIMENTOS}

Os autores agradecem à Coordenação de Aperfeiçoamento de Pessoal de Nível Superior (CAPES) pelo financiamento da pesquisa.

\section{CONFLITOS DE INTERESSES}

Não há conflitos de interesses.

\section{FINANCIAMENTO}

Coordenação de Aperfeiçoamento de Pessoal de Nível Superior

\section{SOBRE OS AUTORES}

Mariana Luíza Becker da Silva é psicóloga, mestra e doutoranda pela Universidade Federal de Santa Catarina. Trabalha na linha de Representações e práticas sociais do Programa de Pós-graduação em Psicologia - PPGP/UFSC.

E-mail: marianaluiza b@hotmail.com

\section{(1) https://orcid.org/0000-0002-5075-982X}

Andréa Barbará da Silva Bousfield é doutora pela Universidade Federal de Santa Catarina e atualmente professora associada na Universidade Federal de Santa Catarina. Trabalha na linha de Representações e práticas sociais do Programa de Pós-graduação em Psicologia - PPGP/UFSC. E-mail: andreabs@gmail.com

\section{(2) http://orcid.org/0000-0002-4333-4719}

Andréia Isabel Giacomozzi é doutora pela Universidade Federal de Santa Catarina e atualmente professora adjunta na Universidade Federal de Santa Catarina. Trabalha na linha de Representações e práticas sociais do Programa de Pós-graduação em Psicologia - PPGP/UFSC. 
E-mail: agiacomozzi@gmail.com

(1) https://orcid.org/0000-0002-3172-5800

Maiara Leandro é psicóloga pela Universidade do Extremo Sul Catarinense, mestranda em Psicologia pela Universidade Federal de Santa Catarina. Trabalha na linha de Representações e práticas sociais do Programa de Pós-graduação em Psicologia - PPGP/UFSC. Recebeu financiamento da Coordenação de Aperfeiçoamento de Pessoal de Nível Superior.

E-mail: maiaraleandro psico@hotmail.com

(2) https://orcid.org/0000-0002-4881-5546 